\title{
"Anti-defamation" group seeks to tame the rambunctious world of online doctor reviews
}

$\mathrm{T}$ hings can get a little ugly at the intersection of medicine and the wild, wild Web. The opinions are unvarnished, the nerves raw and the spelling, well, at times atrocious - at boisterous online sites where patients rate their doctors.

"All he told me was that my son was a spoiled brat," a patient snipes about an Ontario pediatrician.

Physician reviews by patients are a growing phenomenon in a medium where people routinely sound off on vacuum cleaners, restaurants, motel rooms and plumbers.

One United States physician dares to think he can contain this word-of-mouth wildfire. Dr. Jeffrey Segal, a Greensboro, North Carolina, neurosurgeon and founder of Medical Justice, is striking back with a "nondefamation program" that encourages doctors to present patients with waivers prohibiting them from writing online reviews. Some 2000 doctors have signed up for his service, which includes monitoring patient compliance.

Segal's effort may have come too late in the career of the New Brunswick doctor who has this anonymous opinion of him posted on RateMDs.com: "I found him very unprofessional. He called me a Porker when I gained $9 \mathrm{lbs}$ in one month during my pregnancy. He actually BURNED MY BUTT with a lightbulb during a PAP test!"

But it may be of value to the British Columbia pediatrician who is the subject of this biting critique: "He wanted to prescribe a medication to control her gag reflex. When I asked what the possible side effects could be, he replied: 'Well, no side effects, really, but she could die.' I put the prescription down on his desk and walked out."

Segal's waivers have been greeted by the online community like a pernicious computer virus, not to mention an assault on free speech.

He freely admits he's swimming against a tide. "Our challenge is based on the premise that Internet ratings are here to stay - let's do it right," he says. "What we've seen looks more

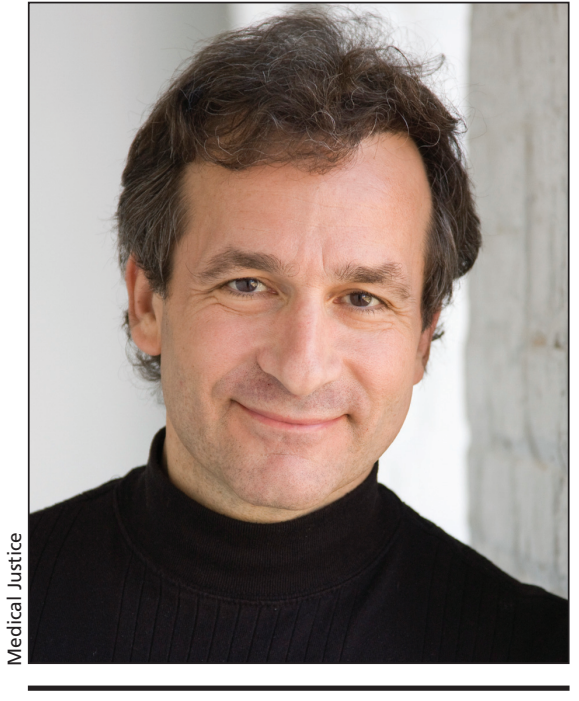

Neurosurgeon Dr. Jeffrey Segal

like the wild wild West, Jerry Springer and The National Enquirer than a serious enterprise. We're trying to provoke a discussion and get it done better."

He's certainly provoked debate; some rating sites have threatened to expose the doctors in his program in online halls of shame. In any event, silencing patients is a hard sell for doctors and not just because the typical review is positive. (Raves such as "Thank God for this great man" outpace the rants.)

Still, a doctor's reputation can be grievously damaged by an anonymous critic with an axe to grind or a skewed account of what went on in an office.

RateMDs, with reviews of more than 190000 doctors internationally, including ones in every state and province, acknowledges on its website that despite its attempts to control stacked-deck and over-the-line postings, "we have no way of knowing who is doing the rating — the doctor, other doctors, patients, dogs, cats, etc."

Boston psychiatrist Jim Sabin, a clinical professor at Harvard Medical School and author of a blog on medical organization ethics, recalled a patient from decades ago who went from one emergency room to another trashing his name. "Anonymous Internet slander would be much worse," but muzzling patients is unseemly, he wrote on his blog. "If a physician greeted me by asking me to sign such a contract, I'd be out of the office in an instant and badmouthing the physician shortly thereafter.'

Dozens of websites offer doctor ratings but their practices differ. Zagat Survey, best known for restaurant ratings built from pithy volunteer reviews, has teamed with the health insurer WellPoint to offer physician ratings to millions of customers. Those reviews come from verified patients, are subject to editorial control and are counted in the scoring only when a doctor has a minimum number of reviews.

Segal hopes ratings will evolve under such conditions. He also wants doctors to have an effective way to respond to negative comments and, in a perfect world, would limit commentary to matters that anyone can reasonably judge. People often don't know the best therapy, for example, but can report whether the doctor washed her hands before an exam or how long another kept his patient waiting.

Now, he says, professionals "have to live through the rumour and innuendo. The doctors need to understand that the system will be credible and accountable."

Health economist Ruth Given studied more than 30 rating sites and concluded many use "quite untrustworthy" information. But they speak to a growing need: Patients say they would far rather learn about a doctor from "people like me" than from official sources. "This may prove to be a very tricky balancing act," she wrote.

Given found that Canadians were more likely than Americans to rate doctors online and tended to be happier with them. To be sure, the patient who slammed an Ontario dermatologist's "disgusting" bedside manner was not happy at all, although another patient found him funny. But that critic's bottom line seems beyond dispute in both countries: "The days of unwavering trust in your MD are over." - Cal Woodward, Washington, DC

DOI:10.1503/cmaj.090679 